\title{
Discriminação racial de jovens negros no Brasil: revisão integrativa
}

\author{
Racial discrimination of young blacks in Brazil: an integrative review \\ Discriminación racial de jóvenes negros en Brasil: una revisión integradora
}

Eliany Nazaré Oliveira

ORCID: https://orcid.org/0000-0002-6408-7243

Universidade Estadual Vale do Acaraú, Brasil

E-mail: elianyy@hotmail.com

Sabrina da Silva França

ORCID: https://orcid.org/0000-0003-1018-0159

Universidade Estadual Vale do Acaraú, Brasil E-mail: sabrinafranca480@gmail.com

Emília do Nascimento Silva

ORCID: https://orcid.org/0000-0003-2951-7655

Universidade Estadual Vale do Acaraú, Brasil

E-mail: silvaemilia213@gmail.com

Caio San Rodrigues

ORCID: https://orcid.org/0000-0001-7423-2515

Universidade Estadual Vale do Acaraú, Brasil

E-mail: caiosanrodrigues2000@gmail.com

Ravena Petra Mororó Ziesemer

ORCID: https://orcid.org//0000-0003-1671-1176

Universidade Estadual Vale do Acaraú, Brasil E-mail: ravenaziesemer3@gmail.com

Ivan Gabriel Sousa Feijó

ORCID: https://orcid.org/0000-0002-1790-4386 Universidade Federal do Ceará, Brasil

E-mail: gabrielsoufee@gmail.com

Francisco Rosemiro Guimarães Ximenes Neto

ORCID: https://orcid.org/0000-0002-7905-9990

Universidade Estadual Vale do Acaraú, Brasil

E-mail: rosemironeto@gmail.com

Maristela Inês Osawa Vasconcelos

ORCID: https://orcid.org/0000-0002-1937-8850

Universidade Estadual Vale do Acaraú, Brasil

E-mail: miosawa@gmail.com

Joyce Mazza Nunes Aragão

ORCID: https://orcid.org/0000-0003-2865-579X

Universidade Estadual Vale do Acaraú, Brasil

E-mail: joycemazza@hotmail.com

Maria Suely Alves Costa

ORCID: https://orcid.org/0000-0002-3545-0613

Universidade Federal do Ceará, Brasil

E-mail: suelypsic@yahoo.com.br

Gleisson Ferreira Lima

ORCID: https://orcid.org/0000-0002-5465-2675

Escola de Saúde Pública Visconde de Saboia, Brasil

E-mail: gleisson_nega@hotmail.com

Juliana Solon Furtado

ORCID: https://orcid.org/0000-0001-5447-5982

Universidade Estadual Vale do Acaraú, Brasil

E-mail: julianasolon@yahoo.com.br

\begin{abstract}
Resumo
O objetivo do presente estudo foi investigar o que apontam as evidências científicas sobre a discriminação racial de jovens negros no Brasil. O método realizado foi uma revisão integrativa da literatura científica, a partir da questão norteadora: o que apontam as evidências científicas sobre a discriminação racial de jovens negros no Brasil? A busca foi realizada em seis bases de dados, sendo adotados como critérios de inclusão artigos originais, sem restrição de período, nos idiomas português, inglês ou espanhol, realizados no Brasil e com texto completo disponível. Excluíramse os estudos incompletos e duplicados. Foram selecionados dez estudos, publicados entre 2003 e 2021, sendo oito artigos científicos e duas dissertações. Seis desses estudos foram publicados em língua portuguesa e quatro em língua inglesa. Evidenciou-se que os estudos analisam as consequências da discriminação racial em três grandes eixos:
\end{abstract}


educação, violência e mercado de trabalho. Conclui-se que os estudos selecionados apontam evidências de que a discriminação racial no Brasil, ainda, é algo recorrente. O quantitativo reduzido de obras, torna-se preocupante, já que o conhecimento científico é de suma importância para compreensão desse fenômeno. Portanto, urge elaboração de mais estudos que abordem o fenômeno da discriminação racial de jovens negros no Brasil.

Palavras-chave: Racismo; Adulto jovem; Brasil.

\begin{abstract}
This study aimed to investigate what scientific evidence exists about racial discrimination against young Blacks in Brazil. The method performed was an integrative review of the scientific literature, based on the guiding question: what does the scientific evidence indicate on racial discrimination against young Blacks in Brazil? The search was performed in six databases, adopting as inclusion criteria original articles, without period restrictions, in Portuguese, English, or Spanish, carried out in Brazil and with full text available. Incomplete and duplicate studies were excluded. Ten studies published between 2003 and 2021 were selected: eight scientific articles and two dissertations. Six of these studies were published in Portuguese and four in English. It was evident that the studies analyzed the consequences of racial discrimination in three main axes: education, violence, and the labor market. It is concluded that the selected studies point to evidence that racial discrimination in Brazil is still something recurrent. The reduced number of works is worrisome since scientific knowledge is of paramount importance for understanding this phenomenon. Therefore, further studies that address the phenomenon of racial discrimination against black youth in Brazil are urgently needed.
\end{abstract}

Keywords: Racism; Young adult; Brazil.

\title{
Resumen
}

Este estudio tuvo como objetivo investigar qué evidencia científica existe sobre la discriminación racial contra los jóvenes negros en Brasil. El método realizado fue una revisión integradora de la literatura científica, a partir de la pregunta orientadora: ¿qué indica la evidencia científica sobre la discriminación racial contra los jóvenes negros en Brasil? La búsqueda se realizó en seis bases de datos, adoptando como criterios de inclusión artículos originales, sin restricciones de período, en portugués, inglés o español, realizados en Brasil y con texto completo disponible. Se excluyeron los estudios incompletos y duplicados. Se seleccionaron diez estudios publicados entre 2003 y 2021: ocho artículos científicos y dos disertaciones. Seis de estos estudios se publicaron en portugués y cuatro en inglés. Se evidenció que los estudios analizaron las consecuencias de la discriminación racial en tres ejes principales: educación, violencia y mercado laboral. Se concluye que los estudios seleccionados apuntan a evidencia de que la discriminación racial en Brasil es todavía algo recurrente. El reducido número de trabajos es preocupante ya que el conocimiento científico es de suma importancia para comprender este fenómeno. Por lo tanto, se necesitan con urgencia más estudios que aborden el fenómeno de la discriminación racial contra los jóvenes negros en Brasil.

Palabras clave: Racismo; Adulto joven; Brasil.

\section{Introdução}

No Brasil, a maioria da população se autodeclara negra, ou seja, preta ou parda, conforme o quesito cor ou raça utilizado pelo Instituto Brasileiro de Geografia e Estatística (IBGE). Porém, ainda assim, o racismo é um fenômeno muito presente, considerado o grande responsável pelos tantos episódios de violência e pelo cenário de exclusão e discriminação em que a população negra brasileira ainda se encontra (Lima, 2020).

O racismo se materializa como discriminação racial (Almeida, 2018), isto é, como ações, atitudes ou manifestações dirigidas a uma ou mais pessoas em razão da cor. Devido à discriminação racial, pessoas negras são vistas como diferentes, consideradas estigmatizadas e inferiorizadas por causa da origem racial (Kilomba, 2019).

A partir da discriminação racial, perpetua-se estrutura racista que incide drasticamente sobre a população negra, determinando-lhe lugares e não lugares que podem ser visitados e ocupados (Panta, 2019). Ou seja, “o espaço urbano e social que o negro ocupa não é o mesmo do branco. A separação é evidente, embora haja um permanente controle para que possa parecer que todos têm o mesmo tipo de acesso a algo de interesse" (Silva, 2006).

A situação se torna ainda mais complexa quando se discorrer acerca de jovens negros e negras, visto que, hoje, estes são os que lideram as estatísticas de pertencimento a famílias pobres e que protagonizam os piores indicadores sociais do país. Aos 21 anos, pessoas negras têm 147\% a mais de chances de seres vítimas de homicídio em relação às pessoas não negras (Cerqueira \& Coelho, 2017). 
Destaca-se que a juventude não se delimita somente pela faixa etária, nem deva ser entendida como cristalizada ou natural, mas como um momento marcado por transformações biológicas, psicológicas, sociais e culturais, "momento em que tem início a vida autônoma do sujeito, que é demarcada por sua entrada no mundo do trabalho" (Abrantes \& Bulhões, 2016).

Em virtude da discriminação racial, alguns jovens negros e negras são ensinados a evitar frequentar alguns espaços, e, em alguns bairros, muitos jovens não sentem tanta segurança, devido ao pouco movimento, medo de pessoas desconhecidas ou de abordagens policiais, o que fazem com eles se sintam inibidos de "circular pela cidade, como se certos espaços fossem 'proibidos' para eles ou como se eles não devessem estar em determinados lugares” (Lage \& Cota, 2020).

Diante desse contexto, torna-se imprescindível a investigação do impacto da discriminação racial nessa faixa populacional, a fim de apresentar em que âmbitos a juventude negra se torna mais vulnerável, devido à cor ou raça, a enfrentar a discriminação racial "de forma sistematizada e planejada, abarcando políticas que envolvam as diversas dimensões da vida dos jovens, bem como garantindo igualdade racial e oportunidades iguais" (Brasil, 2018).

A partir do exposto, objetivou-se investigar o que apontam as evidências científicas sobre a discriminação racial de jovens negros no Brasil.

\section{Metodologia}

Este estudo trata-se de revisão integrativa da literatura científica, cujas etapas de construção seguiram um modelo previamente estabelecido, com intuito de manter o rigor metodológico, apresentadas a seguir: 1) elaboração da pergunta de pesquisa; 2) definição dos critérios de inclusão de estudos e seleção da amostra (busca ou amostragem na literatura); 3) representação dos estudos selecionados em formato de tabelas, considerando todas as características em comum (coleta de dados); 4) análise crítica dos estudos incluídos, identificando diferenças e conflitos; 5) interpretação/discussão dos resultados; 6) apresentação da revisão integrativa de forma clara e objetiva (evidências/dados encontrados) (Souza et al., 2010).

A questão norteadora do estudo foi: o que apontam as evidências científicas sobre a discriminação racial de jovens negros no Brasil? Para construção dessa questão de pesquisa, utilizou-se da estratégia Population, Interest e Context (PICo) para uma revisão integrativa, em que P refere-se aos participantes (jovens negros); I, ao fenômeno de interesse (discriminação racial); e Co, ao contexto de estudo relacionado à realidade brasileira (Oliveira Araújo, 2020).

Assim, consideram-se jovens negros indivíduos com idade entre 15 e 29 anos que se autodeclaram pretos ou pardos, a partir dos seguintes critérios: "jovens" enquanto pessoas com idade entre 15 (quinze) e 29 (vinte e nove) anos, conforme proposto pelo Estatuto da Juventude, instituído pela Lei no 12.852, de 5 de Agosto de 2013(Brasil, 2013); "população negra" enquanto "o conjunto de pessoas que se autodeclaram pretas e pardas, conforme o quesito cor ou raça usado pela Fundação Instituto Brasileiro de Geografia e Estatística (IBGE), ou que adotam autodefinição análoga” (Brasil, 2010), de acordo com a Lei $n^{\circ} 12.288$, de 20 de Julho de 2010, que institui o Estatuto da Igualdade Racial.

Como "discriminação racial", considerou-se o conceito proposto por Silva (Silva, 2001), em que esta é "a materialização da crença racista em atitudes que efetivamente limitam ou impedem o desenvolvimento humano pleno das pessoas pertencentes ao grupo discriminado".

Para o conceito do Brasil, considerou-se como "uma República Federativa organizada política e administrativamente em estados, municípios e distritos. Os 26 estados brasileiros, além do Distrito Federal, compõem a República Federativa do Brasil", de acordo com o proposto pelo IBGE (Instituto Brasileiro de Geografia e Estatística, 2021).

Com base nestas definições, adotou-se os seguintes critérios de inclusão: artigos originais; sem restrição de período; nos idiomas português, inglês ou espanhol; realizados no Brasil; e que tivessem o texto completo disponível. Excluíram-se os estudos incompletos e duplicados.

A busca pelos estudos foi realizada de agosto a setembro de 2021. Os descritores foram escolhidos com base no tema 
central, "A discriminação racial de jovens negros no Brasil", e a partir de consulta aos Descritores em Ciências da Saúde (DeCS) e ao Medical Subject Headings (MeSH). Desta forma, selecionaram-se os seguintes descritores: "Young adult", "Youth", "Teenage", "Racism", "Racial prejudice", "Discrimination racial", "Prejudice" e "Brazil". Para ampliar o alcance das buscas, usaram-se os operadores boleanos "AND" e "OR". O cruzamento adotado para a pesquisa foi: "“"Young adult" OR "Youth" OR “Teenage") AND ("Racism" OR "Racial prejudice" OR "Discrimination racial” OR "Prejudice") AND Brazil".

Incluíram-se as bases de dados: Scientific Electronic Library Online (SciELO), Ciências da Saúde da América Latina e Caribe (LILACS), Medical Literature Analysis and Retrieval System Online (MEDLINE), SciVerse Scopus, da Elsevier (Scopus) e Education Resources Information Center (ERIC). A literatura cinza foi consultada pelo banco de teses e dissertações do portal da Coordenação de Aperfeiçoamento de Pessoal de Nível Superior (CAPES).

A seleção dos estudos foi realizada conforme o método do Preferred Reporting Items for Systematic Reviews and Meta-Analyses (PRISMA) (Galvão et al., 2015). Além disso, a fim de realizar coleta de dados mais completa, adaptou-se instrumento para coleta de dados dos estudos incluídos (Ursi \& Gavão, 2006).

O estudo seguiu os princípios éticos estabelecidos pela Resolução 510/2016 do Conselho Nacional de Saúde (CNS) que envolve o uso de dados disponibilizados para domínio público (Brasil, 2016).

\section{Resultados}

Com a busca nas bases de dados, 449 estudos foram identificados. Logo após a leitura de título e resumo, excluíramse oito publicações por duplicidade, assim, selecionaram-se 39, de acordo com os critérios de inclusão e exclusão. A partir de análise na íntegra, elegeram-se 10 estudos, conforme a questão norteadora.

A seleção e busca dos estudos desta revisão nortearam-se pelo fluxograma, Figura 1, do Preferred Reporting Items for Systematic Reviews and Meta-Analyses (PRISMA) (Galvão et al., 2015).

Figura 1. Fluxograma de busca e seleção de obras, de acordo com as recomendações do PRISMA.

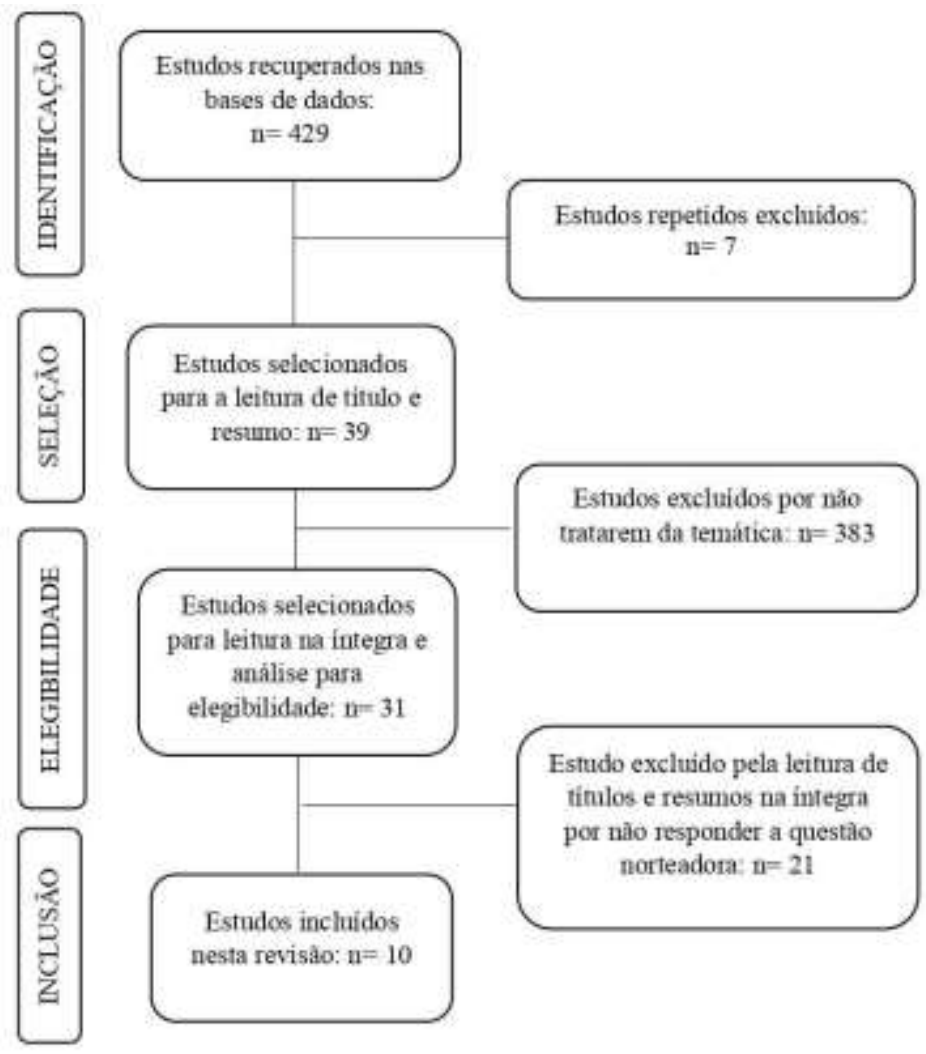

Fonte: Autores. 
Os dez estudos selecionados foram publicados entre os anos de 2003 e 2021, sendo oito artigos científicos e duas monografias. Dentre estes, encontram-se pesquisas qualitativas, revisão bibliográfica, análise de dados divulgados na internet e dados de pesquisas, ensaios e recorte de pesquisa. Seis desses estudos foram publicados em português e quatro em inglês. As características dos estudos podem ser visualizadas no Quadro 1.

Quadro 1.

\begin{tabular}{|c|c|c|c|c|c|}
\hline Estudos & Títulos & Ano & Autores & Tipo de obra & Métodos \\
\hline 1 & $\begin{array}{l}\text { Intersection of Race and Gender } \\
\text { in Self-Reports of Violent } \\
\text { Experiences } \\
\text { Polyvictimization by Young Girls } \\
\text { in Brazil }\end{array}$ & 2021 & $\begin{array}{l}\text { Ramos, DO; } \\
\text { Goes, EF; } \\
\text { Ferreira, AJF }\end{array}$ & Artigo & Pesquisa qualitativa \\
\hline 2 & $\begin{array}{l}\text { Necroeducação: reflexões sobre a } \\
\text { morte do negro no sistema } \\
\text { educacional brasileiro }\end{array}$ & 2020 & $\begin{array}{l}\text { Costa, AP; } \\
\text { Martins, CHS; } \\
\text { Silva, HC }\end{array}$ & Artigo & Ensaio \\
\hline 3 & $\begin{array}{l}\text { Fora do jogo? jovens negros no } \\
\text { mercado de trabalho }\end{array}$ & 2003 & $\begin{array}{l}\text { Santos, EF; } \\
\text { Scopinho, RA }\end{array}$ & Artigo & $\begin{array}{c}\text { Revisão } \\
\text { bibliográfica }\end{array}$ \\
\hline 4 & $\begin{array}{l}\text { Discrimination, color and social } \\
\text { intervention among youth in the } \\
\text { city of Rio de Janeiro (RJ, } \\
\text { Brazil): the male perspective }\end{array}$ & 2006 & $\begin{array}{l}\text { Cecchetto, F; } \\
\text { Monteiro, S }\end{array}$ & Artigo & Pesquisa qualitativa \\
\hline 5 & $\begin{array}{l}\text { Dispositivo de Segurança e } \\
\text { Racionalidade Necrobiopolítica: } \\
\text { Narrativas de Jovens Negros de } \\
\text { Fortaleza }\end{array}$ & 2020 & $\begin{array}{l}\text { Costa, AF; } \\
\text { Barros, JPP; } \\
\text { Silva, DB; } \\
\text { Benicio, LFS; } \\
\text { Moreira, MGR }\end{array}$ & Artigo & Pesquisa qualitativa \\
\hline 6 & $\begin{array}{l}\text { O Preconceito racial e a trajetória } \\
\text { de escolarização na perspectiva } \\
\text { de adolescentes e jovens negros }\end{array}$ & 2016 & Lima, MG & Dissertação & $\begin{array}{l}\text { Pesquisa qualitativa, } \\
\text { com perspectiva de } \\
\text { intervenção }\end{array}$ \\
\hline 7 & 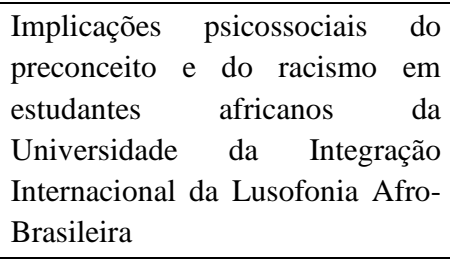 & 2017 & Mendonça, FWO & Dissertação & Pesquisa qualitativa \\
\hline 8 & $\begin{array}{l}\text { Violência e Racismo: novas faces } \\
\text { de uma afinidade reiterada }\end{array}$ & 2018 & $\begin{array}{l}\text { Sinhoretto, J; } \\
\text { Morai, DS }\end{array}$ & Artigo & $\begin{array}{l}\text { Estudo de métodos } \\
\text { mistos }\end{array}$ \\
\hline 9 & $\begin{array}{l}\text { Racismo e julgamento social na } \\
\text { internet: crianças e jovens negros } \\
\text { como alvos }\end{array}$ & 2017 & $\begin{array}{l}\text { Farias, JWF; } \\
\text { Sousa, RS; } \\
\text { Lima, TJS; } \\
\text { Santos, WS; } \\
\text { Ferreira, SC }\end{array}$ & Artigo & $\begin{array}{l}\text { Estudo de métodos } \\
\text { mistos }\end{array}$ \\
\hline 10 & $\begin{array}{l}\text { The vicious circle: effects of race } \\
\text { and class on university entrance } \\
\text { in Brazil }\end{array}$ & 2017 & Valente, RR & Artigo & Pesquisa qualitativa \\
\hline
\end{tabular}

Fonte: Autores. 
Os estudos analisam as consequências da discriminação racial em três grandes eixos: educação, violência e mercado de trabalho, distribuídos conforme Figura 2. Consoante ao Quadro 2, os trabalhos voltados ao setor educacional trouxeram a perspectiva de racismo em ambientes como universidades e escolas, além de panorama sobre as políticas de intervenção dessas instituições com relação a essa problemática (Costa et al., 2020; Lima, 2016; Mendonça, 2017; Valente, 2017). Quanto à violência, destaca-se a severa atuação policial contra jovens negros (Costa et al., 2020; Sinhoretto \& Morais, 2018), assim como a intimidação verbal imposta pela sociedade no cotidiano dos jovens e, até mesmo, em ambiente virtual (Farias et al., 2017; Oliveira Ramos et al., 2021). Por conseguinte, o mercado de trabalho, segundo os estudos, tem se configurado como ambiente de poucas oportunidades e baixas perspectivas de desenvolvimento profissional para os jovens negros (Cecchetto \& Monteiro, 2006; Santo \& Scopinho, 2011).

Figura 2. Principais temáticas abordadas nos estudos. Brasil, 2003 a 2021.

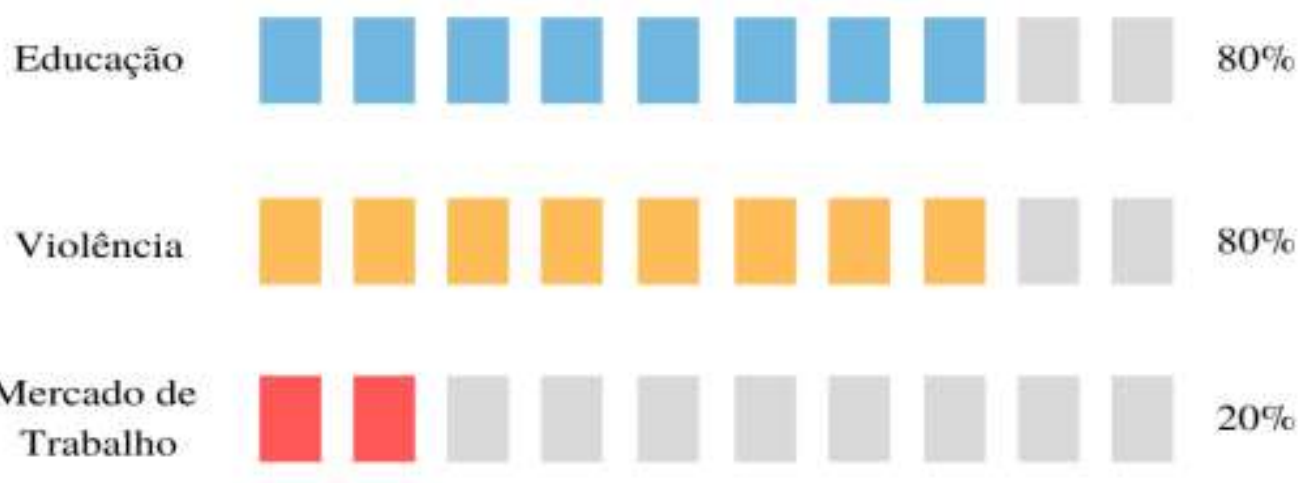

Fonte: Autores. 
Quadro 2. Apresentação dos estudos, conforme objetivos e principais resultados. Brasil, 2003 a 2021.

\begin{tabular}{|c|c|c|}
\hline Estudos & Objetivos & Principais resultados \\
\hline 1 & $\begin{array}{l}\text { Explorar as disparidades raciais em } \\
\text { autorrelatos de vitimização violenta e } \\
\text { polivitimização entre meninas no Brasil e } \\
\text { analisar a distribuição das taxas de prevalência } \\
\text { entre os grupos raciais e as chances estimadas } \\
\text { de exposição. }\end{array}$ & $\begin{array}{l}\text { Os negros tiveram as maiores taxas de denúncias, sendo intimidação e } \\
\text { polivitimização. As meninas negras eram o grupo com maior } \\
\text { prevalência de bullying, em que relataram ser intimidadas pela raça e } \\
\text { também tiveram a maior prevalência de relatos de polivitimização. } \\
\text { Raça/cor da pele está associado a todas as formas de vitimização e } \\
\text { polivitimização. }\end{array}$ \\
\hline 2 & $\begin{array}{l}\text { Debater processos de invisibilização do jovem } \\
\text { negro no sistema educacional brasileiro e as } \\
\text { respectivas contribuições para outras formas de } \\
\text { morrer no contexto de uma sociedade marcada } \\
\text { pelo racismo estrutural. }\end{array}$ & $\begin{array}{l}\text { Observam-se as escolas e os diversos mecanismos, como materiais } \\
\text { didáticos, instrumentos, construção curricular e pedagógica práticas, } \\
\text { nota-se que ainda hoje os negros são sub-representações, apagados e } \\
\text { estereotipada, o que estabelece educação para a morte, uma } \\
\text { necroeducação. }\end{array}$ \\
\hline 3 & $\begin{array}{l}\text { Analisar a realidade do negro no mercado } \\
\text { formal de trabalho, a partir do resgate de como } \\
\text { se construiu este mercado no Brasil. }\end{array}$ & $\begin{array}{l}\text { As desigualdades raciais tornam-se evidentes quando são analisadas ao } \\
\text { mercado de trabalho, em que os jovens negros têm participado de modo } \\
\text { excludente, em condições precárias e desiguais em relação aos brancos. } \\
\text { O desemprego é mais frequente entre eles, assim como a informalidade, } \\
\text { menores salários e funções subalternas. }\end{array}$ \\
\hline 4 & $\begin{array}{l}\text { Analisar as questões da discriminação e do } \\
\text { racismo entre os jovens do Rio de Janeiro, } \\
\text { examinando as percepções, experiências e } \\
\text { reações do grupo às situações em que } \\
\text { enfrentaram a discriminação. }\end{array}$ & $\begin{array}{l}\text { Os jovens atribuem o desencadeamento de atitudes discriminatórias à } \\
\text { condição social e à cor. O mercado de trabalho é identificado } \\
\text { como lugar difícil para a cor. Em relação aos sentimentos e reações } \\
\text { frente à discriminação, prevaleceram sentimentos de humilhação, } \\
\text { constrangimento, tristeza e desconforto. }\end{array}$ \\
\hline 5 & \begin{tabular}{lll} 
Problematizar & \multicolumn{2}{c}{ racionalidades ligadas à } \\
implantação das Células de Proteção \\
Comunitária & (CPC), nas periferias de \\
Fortaleza-CE. & &
\end{tabular} & $\begin{array}{l}\text { Foram recorrentes os relatos dos(as) jovens negros(as) moradores do } \\
\text { Jangurussu acerca do recrudescimento de uma tendência de } \\
\text { criminalização de jovens negros a partir da instalação da CPC. } \\
\text { Aumento das abordagens policiais pela CPC a jovens negros, tratando } \\
\text { esses que circulam naquela região como "elementos suspeitos". Na } \\
\text { perspectiva do(a)s participantes, a instalação da CPC tem o intuito de } \\
\text { tentar circunscrever a violência à periferia. }\end{array}$ \\
\hline 6 & $\begin{array}{l}\text { Analisar as concepções e crenças de jovens } \\
\text { negros/as com relação ao preconceito racial e } \\
\text { as possíveis implicações na trajetória de } \\
\text { escolarização. }\end{array}$ & $\begin{array}{l}\text { Os participantes da pesquisa foram unânimes em afirmar sobre a } \\
\text { existência de preconceito racial no Brasil, sendo associada à cor da } \\
\text { pele, com percepções particularizadas e não o associando como prática } \\
\text { criminosa. Dificuldade da escola em intervir em situações de } \\
\text { discriminação racial, contudo, todos afirmaram que o racismo, em } \\
\text { nenhum momento, influenciou as respectivas trajetórias de } \\
\text { escolarização, mesmo sendo perceptível uma crise ética com relação à } \\
\text { política de cotas. }\end{array}$ \\
\hline 7 & $\begin{array}{l}\text { Analisar as implicações psicossociais do } \\
\text { preconceito e do racismo nos estudantes } \\
\text { africanos da UNILAB. }\end{array}$ & $\begin{array}{l}\text { Homogeneização dos estudantes ao serem vistos como um grupo } \\
\text { supostamente único, percebidos simplesmente como "os africanos". } \\
\text { Relatam dificuldades na participação em grupos de trabalho e nas } \\
\text { atividades desenvolvidas na universidade, como eventos contemplação } \\
\text { de bolsas. Ao serem tratados de forma exótica, relatam sentimento de } \\
\text { vergonha, assim como sofrimento íntimo de rebaixamento por } \\
\text { humilhação e medo de violência física. }\end{array}$ \\
\hline 8 & $\begin{array}{l}\text { Reunir evidências de novas faces da relação } \\
\text { entre violência e racismo. }\end{array}$ & $\begin{array}{l}\text { Os dados apontam a discrepância da experiência com a violência entre } \\
\text { brancos e negros, com aprofundamento da desigualdade racial expresso } \\
\text { pelos indicadores sociais da violência. O predomínio da vigilância } \\
\text { policial sobre jovens negros também é constatado pelas altas taxas de } \\
\text { encarceramento em comparação a adultos brancos. }\end{array}$ \\
\hline 9 & $\begin{array}{l}\text { Avaliar o preconceito racial, retratado nas } \\
\text { notícias, contra crianças e jovens negros em } \\
\text { conflito com a Lei, mediante o julgamento } \\
\text { social atribuído. }\end{array}$ & $\begin{array}{l}\text { Resultados divididos em três classes: classe } 1 \text { - "A solução para o } \\
\text { problema social", considerando "matar" as crianças e jovens retratados } \\
\text { nas notícias; classe } 2 \text { - sobre "A responsabilização dos pais e da Lei" ao } \\
\text { fato do crime ser cometido por menores, destacando a ausência dos pais } \\
\text { e de leis mais rígidas; classe } 3 \text { - sobre "A responsabilização da Política } \\
\text { e dos Direitos Humanos", aos comentários sobre política e a influência } \\
\text { desta, na visão dos usuários e leitores, no evento descrito pela notícia. }\end{array}$ \\
\hline 10 & $\begin{array}{l}\text { Examinar a relação entre raça e acesso ao } \\
\text { ensino superior de estudantes entre } 2004 \text { e } \\
2008 \text {, com dados da pesquisa nacional do } \\
\text { Exame Nacional do Brasil } \\
\text { Ensino Médio (ENEM). }\end{array}$ & $\begin{array}{l}\text { Os alunos não brancos têm notas mais baixas no ENEM e avaliam a } \\
\text { qualidade geral do ensino médio mais negativamente do que os alunos } \\
\text { brancos. }\end{array}$ \\
\hline
\end{tabular}

Fonte: Autores.

Além disso, com relação à abrangência geográfica dos estudos, cinco deles foram realizados em nível nacional; dois no âmbito estado do Ceará; dois, no estado do Rio de Janeiro; e um, no Distrito Federal, conforme Quadro 3. 
Quadro 3. Distribuição geográfica dos estudos selecionados, com base na abrangência. Brasil, 2003 a 2021.

\begin{tabular}{|c|c|c|}
\hline Estudos & Tipo de abrangência & Locais \\
\hline 1 & Nacional & Brasil \\
\hline 2 & Nacional & Brasil \\
\hline 3 & Estadual & Rio de Janeiro \\
\hline 4 & Estadual & Rio de Janeiro \\
\hline 5 & Estadual & Ceará \\
\hline 6 & Estadual & Distrito Federal \\
\hline 7 & Nacional & Brasil \\
\hline 8 & Nacional & Brasil \\
\hline 9 & Estadual & Ceará \\
\hline 10 & Nacional & Brasil \\
\hline
\end{tabular}

Fonte: Autores.

\section{Discussão}

No Quadro 1, apresenta-se a distribuição das características do material encontrado, de acordo com título, ano de publicação, autores, tipo de estudo e método. A partir deste, percebeu-se que a maioria dos estudos foi publicada na forma de artigos e o ano com mais obras inclusas foi 2017. Isto pode ter relação com o fato de que, de acordo com alguns autores, 2017 ter sido um dos anos em que mais se discutiu racismo na sociedade, sobretudo, devido ao número de despejos violentos que a população negra sofreu durante o ano (Vieira \& Ostetto, 2020).

Referente à distribuição dos trabalhos de acordo com as áreas abordadas, observa-se, em primeiro lugar, que o sistema educacional se apresentou como um meio de grande potencial para disseminação da discriminação racial, apesar da vigência da Lei Federal no. 10.639/03, a qual inclui, obrigatoriamente, aulas didáticas com temáticas advindas da "História e Cultura AfroBrasileira", na grade curricular dos sistemas educativos (Brasil, 2003).

Essa ação, apesar de extrema relevância, não foi suficiente para intervir de maneira eficaz sobre o preconceito racial sofrido por jovens negros nos ambientes educacionais (Campos et al., 2018). Com base na análise da literatura, identificou-se que ainda existe considerável estigmatização e exclusão de pessoas negras nesses espaços, seja por conta da maior representação de pessoas brancas em materiais didáticos ou da figura do negro sempre correlacionada ao período de escravidão (Vieira \& Ostetto, 2020).

Somado a isso, pode-se afirmar que a dificuldade das instituições de ensino em intervir em situações de discriminação racial também se configura como fator determinante para o agravamento da problemática da discriminação racial. Deste modo, a presença do racismo dentro do setor educacional emerge como algo a ser considerado, principalmente porque, às vezes, essa realidade é mascarada ou negada, em virtude da associação com outras formas de preconceitos, como a xenofobia e o bullying (Carapello, 2020).

Além disso, observou-se que o mercado de trabalho é um setor que se destaca pela caracterização de oportunidades desiguais, atuando de forma excludente, com condições precárias para a população negra. Assim, mesmo com o desenvolvimento de estratégias, como o projeto elaborado no Estado de São Paulo, a fim de traçar ações para identificação e intervenção da inclusão de jovens negros no mercado de trabalho, ainda se tem a necessidade de aprimoramento das políticas públicas voltadas para estas questões (São Paulo, 2018).

Isso se evidencia em pesquisa que apresenta a democracia racial como um mito na sociedade brasileira, pois os cargos empresariais mais elevados têm predominância branca. Em contrapartida, os cargos mais baixos da pirâmide organizacional dessas empresas são ocupados, em grande maioria, por pessoas negras (Machado Júnior et al., 2018). 
Outro campo abordado nos estudos diz respeito à violência sofrida por jovens negros e negras, advinda, sobretudo, de instituições de segurança pública e da justiça criminal, que uniformiza os jovens negros como alvos de intensa vigilância.

Assim, elucida-se que a juventude negra é vista socialmente a partir de uma dualidade: ora é enquadrada como um "risco social", ou seja, como alguém que pode se tornar um desvio para a sociedade, um infrator desviante das normas e leis; ora como um "problema social" a ser resolvido, como se todos os jovens negros e negras já estivessem em situação de infração e desvio, necessitando de melhores condições de vida (Pimenta, 2014).

A partir disso, cria-se um pré-julgamento sobre a juventude negra, que resulta, por exemplo, em práticas agressivas e intimidadoras por parte da segurança policial, até mesmo se referindo a negros e negras como "elementos suspeitos", em alguns casos (Cavalcante, 2019), e resultando, na maioria das vezes, em ações discriminatórias e no elevado número de homicídios dessa população (Brasil, 2015).

Desse modo, estudo apresenta, a partir de relatos de jovens negros e negras moradores de três capitais brasileiras, práticas policiais contra essas pessoas, revelando, assim, o racismo manifestado da sociedade, ou seja, "os jovens negros vivem as consequências desse processo no seu cotidiano, notadamente quando se defrontam com a presença da polícia" (Anunciação et al., 2020).

Também, em relação à questão da violência, sobretudo, ao considerar o Quadro 2, que aprofunda a análise e discussão dos estudos, conforme objetivos e principais resultados, notou-se o modo como a sociedade, por meio de comentários violentos na internet, se comporta de forma discriminatória referente aos jovens negros, principalmente aqueles que se encontram em conflito com a lei. Pode-se perceber que o advento da internet deu margens à liberdade de expressão, contudo, diversas pessoas a utilizam de forma negativa, expondo opiniões e comentários ofensivos, sem buscar compreender maiores detalhes sobre determinadas situações e se refugiando no anonimato proporcionado pelas redes ao incitar o discurso de ódio (Paiva et al., 2019). Desta forma, a situação criminal, muitas vezes multifatorial, é associada somente à cor da pele do infrator (Cerqueira \& Coelho, 2017).

Verificou-se, também, mediante os resultados, que quatro estudos apontam como jovens negros e negras são excluídos e sub-representações nos espaços sociais brasileiros, não tendo direito à aceitação social. A estes, é negada a participação ativa em momentos singulares, silenciando-os ou thes restringindo a um direito de voz inferior ao concedido aos jovens brancos (Cecchetto \& Monteiro, 2006; A. P. Costa et al., 2020; Mendonça, 2017; Santo \& Scopinho, 2011).

A aceitação social possui impactos significativos sobre a vida de cada indivíduo, proporciona maior bem-estar, fomenta o crescimento pessoal e, até mesmo, diminui os riscos de morbidade e mortalidade, pois impacta significativamente na saúde. Indivíduos socialmente aceitos apresentam, até mesmo, menos queixas sintomáticas físicas e psíquicas (Damasceno \& Zanello, 2018). Portanto, torna-se notório o caráter prejudicial que a sociedade brasileira assume com essa faixa populacional, visto que o impacto da discriminação e, consequentemente, a exclusão imposta aos jovens negros pode tornar-se desastroso, prejudicando o desenvolvimento e propiciando, inclusive, situações de adoecimento.

Destarte, convém mencionar que alguns artigos (Cecchetto \& Monteiro, 2006; Mendonça, 2017) abordam os sentimentos dessa população frente às experiências de discriminação, ressaltando a humilhação, a tristeza, o constrangimento e o medo da violência física que tal situação impõe. Para estudiosos da área, o racismo é concomitantemente um fenômeno presente e culmina em experiência de estresse contínuo durante a vida de toda a população negra, cujos efeitos deletérios são capazes de gerar experiência traumática, de efeito cumulativo, com grandes chances de impactar significativamente na saúde mental dos indivíduos (Damasceno \& Zanello, 2018).

\section{Considerações Finais}

O presente estudo apresentou investigação acerca do que apontam as evidências científicas sobre a discriminação 
racial de jovens negros no Brasil, apontando que este fenômeno ainda é algo recorrente no país. Os jovens negros sofrem com os empecilhos advindos do racismo em diversos âmbitos, como ambiente escolar, mercado de trabalho e presídios, além de serem constantes alvos de violências, como agressão verbal, moral, física e psicológica.

Nesse contexto, a revisão mostra que a juventude negra assiduamente é privada de direitos, silenciada, mal representada e invalidada na sociedade brasileira. Infere-se, também, que esta realidade impacta sobre a saúde psicológica, emocional e física de jovens negros e negras, ocasionando constante estado de estresse, com diversos efeitos deletérios.

Assim, salienta-se a necessidade da criação de políticas públicas voltadas à juventude negra, de modo a fortalecer as redes de proteção social e diminuir as vulnerabilidades vivenciadas por esses jovens, a partir da discriminação racial.

Ademais, outro fator de importante menção é a ausência de trabalhos que tenham como objeto a discriminação racial sofrida por jovens negros na maioria dos estados brasileiros, assim como o número reduzido de estudos encontrados acerca da temática nas bases de dados, o que se configura como a principal limitação desta revisão. O quantitativo reduzido de publicações torna-se preocupante, já que o conhecimento científico é de suma importância para compreensão e análise da multicausalidade desse fenômeno, além de empoderar o público a lutar por igualdade e dignidade.

As pesquisas de abrangência nacional são eficientes em mostrar um panorama da problemática no país, mas é somente compilando trabalhos de abrangência geográfica limitada que se tem a possibilidade de avaliar a dimensão das disparidades existentes entre a discriminação sofrida por jovens negros e negras em cada região do país.

Por fim, urge a elaboração de mais estudos que abordem sobre o tema, principalmente, que possuam dimensão geográfica limitada, de modo a alcançar perspectiva mais detalhada sobre a questão da discriminação racial da juventude negra no Brasil.

\section{Agradecimentos}

A Universidade Estadual Vale do Acaraú e ao Programa de Iniciação Científica vinculado ao Programa de Bolsas de Permanência Universitária (PICPBPU/UVA)

\section{Referências}

Abrantes, A. A., \& Bulhões, L. (2016). Idade adulta e o desenvolvimento psíquico na sociedade de classes: juventude e trabalho. In L. M. Martins, A. A. Abrantes, \& M. G. D. Facci (Eds.), Periodização histórico-cultural do desenvolvimento psíquico: do nascimento à velhice. Autores Associados.

Almeida, S. L. (2018). O que é racismo estrutural? Letramento.

Anunciação, D., Trad, L. A. B., \& Ferreira, T. (2020). "Mão na cabeça!": abordagem policial, racismo e violência estrutural entre jovens negros de três capitais do Nordeste. Saúde e Sociedade, 29(1). https://doi.org/10.1590/s0104-12902020190271

Brasil. (2003). Lei no 10.639, de 9 de janeiro de 2003. Altera a Lei no 9.394, de 20 de dezembro de 1996, que estabelece as diretrizes e bases da educação nacional, para incluir no currículo oficial da Rede de Ensino a obrigatoriedade da temática 'História e Cultura Afro-Brasileira', e dá outras providências. In Diário Oficial da União (Lei No. 10.639). http://www.planalto.gov.br/ccivil_03/leis/2003/110.639.htm

Brasil. Conselho Nacional de Saúde. (2016). Resolução no 510, de 07 de Abril de 2016 (Brasil \& Conselho Nacional de Saúde, Eds.). Brasil.

Brasil, \& Presidência da República. (2010). Lei n.o 12.228. Institui o Estatuto da Igualdade Racial; altera as Leis nos 7.716, de 5 de janeiro de 1989, 9.029, de 13 de abril de 1995, 7.347, de 24 de julho de 1985, e 10.778, de 24 de novembro de 2003. In Brasil. Presidência da República (Lei No. 12.228). http://www.planalto.gov.br/ccivil_03/_ato2007-2010/2010/lei/112288.htm

Brasil. Presidência da República. (2013). Lei no 12.852. Dos direitos e das políticas públicas de juventude. In Brasil. Presidência da República. Lei no 12.852. Presidência da República. http://www.planalto.gov.br/ccivil_03/_ato2011-2014/2013/lei/112852.htm

Brasil. Presidência da República. (2015). Mapa do encarceramento: os jovens do Brasil. Secretaria Geral da Presidência da República. Secretaria Nacional de Juventude, Eds.). Presidência da República.

Brasil. Secretaria Nacional de Juventude. (2018). Plano Juventude Viva: um levantamento histórico. Secretaria Nacional de Juventude. Plano Juventude Viva: um levantamento histórico

Campos, M. A. S., Pereira, L. J., \& Souza, C. M. (2018). A cultura afro-brasileira nos estabelecimentos de ensino médio: uma experiência de resistência e silêncios do PNFEM. Revista GeoPantanal, 25, 147-164. 
Carapello, R. (2020). O racismo camuflado pelo bullying. Revista Educação - UNG-Ser, 15(1). https://doi.org/10.33947/1980-6469-v15n1-4018

Cavalcante, A. R. (2019). Corpos enforcados, destroçados e desaparecidos: violência contra jovens negros em Salvador. Dissertação de Mestrado, Universidade Católica do Salvador, Salvador, Brasil. http://ri.ucsal.br:8080/jspui/bitstream/prefix/1723/1/TESEANDARA\%c3\%8dCAVALVANTE.pdf

Cecchetto, F., \& Monteiro, S. (2006). Discrimination, color and social intervention among youth in the city of Rio de Janeiro (RJ, Brazil): the male perspective. Revista Estudos Feministas, 14(1), 199-218.

Cerqueira, D., \& Coelho, D. S. C. (2017). Democracia racial e homicídios de jovens negros na cidade partida, Texto para Discussão, No. 2267. Instituto de Pesquisa Econômica Aplicada.

Costa, A. F., Barros, J. P. P., Silva, D. B., Benicio, L. F. de S., \& Moreira, M. G. R. (2020). Dispositivo de Segurança e Racionalidade Necrobiopolítica: Narrativas de Jovens Negros de Fortaleza. Psicologia: Ciência e Profissão, 40(spe). https://doi.org/10.1590/1982-3703003230162

Costa, A. P., Martins, C. H. S., \& Silva, H. C. (2020). Necroeducação: reflexões sobre a morte do negro no sistema educacional brasileiro. Revista Brasileira de Educação, 25. https://doi.org/10.1590/s1413-24782020250043

Damasceno, M. G., \& Zanello, V. M. L. (2018). Saúde Mental e Racismo Contra Negros: Produção Bibliográfica Brasileira dos Últimos Quinze Anos. Psicologia: Ciência e Profissão, 38(3). https://doi.org/10.1590/1982-37030003262017

Farias, J. W. F., Sousa, R. S., Lima, T. J. S., Santos, W. S., \& Ferreira, S. C. (2017). Racismo e julgamento social na internet: crianças e jovens negros como alvos. Revista de Psicologia, 8(2), 119-128.

Galvão TF, Pansani TSA, \& Harrad D. (2015). Principais itens para relatar Revisões sistemáticas e Meta-análises: A recomendação PRISMA. Epidemiologia e Serviços de Saúde, 24(2). https://doi.org/10.5123/S1679-49742015000200017

Instituto Brasieiro de Geografia e Estatística. (2021). IBGE - Educa . Instituto Brasieiro de Geografia e Estatística. https://educa.ibge.gov.br/criancas/brasil/nosso-territorio/19637-divisao-territorial.html

Kilomba, G. (2019). Memórias da plantação: episódios de racismo cotidiano. Editora Cobogó.

Lage, D. G. V., \& Cota, D. A. (2020). Juventude negra periférica e direito à cidade: um estudo de caso. Cadernos de Arquitetura e Urbanismo, 26(39). https://doi.org/10.5752/P.2316-1752.2019v26n39p106

Lima, M. (2016). O Preconceito racial e a trajetória de escolarização na perspectiva de adolescentes e jovens negros. Dissertação de Mestrado, Instituto CEUB de pesquisa e Desenvolvimento, Brasília, Brasil.

Lima, M. E. O. (2020). Psicologia social do preconceito e do racismo. Blucher.

Machado Júnior, C., Bazanini, R., \& Mantovani, D. M. N. (2018). The myth of racial democracy in the labour market: a critical analysis of the participation of afro-descendants in brazilian companies. Organizações \& Sociedade, 25(87). https://doi.org/10.1590/1984-9250875

Mendonça, F. (2017). Implicações psicossociais do preconceito e do racismo em estudantes africanos da universidade da integração Internacional da lusofonia afro-brasileira. Dissertação de Mestrado, Universidade Federal do Ceará, Fortaleza, Brasil.

Oliveira Araújo, W. C. (2020). Recuperação da informação em saúde. ConCI: Convergências Em Ciência Da Informação, 3(2). https://doi.org/10.33467/conci.v3i2.13447

Oliveira Ramos, D., Goes, E. F., \& Ferreira, A. J. F. (2021). Intersection of Race and Gender in Self-Reports of Violent Experiences and Polyvictimization by Young Girls in Brazil. Journal of Racial and Ethnic Health Disparities. https://doi.org/10.1007/s40615-021-01089-2

Paiva, P. D., Silva, V. M., \& Moura, R. S. (2019). Detecção automática de discurso de ódio em comentários online. Anais Da VII Escola Regional de Computação Aplicada à Saúde, 157-162. https://sol.sbc.org.br/index.php/ercas/article/view/9052/8954

Panta, M. (2019). População negra e o direito à cidade: interfaces sobre raça e espaço urbano no Brasil. Acervo, 33(1), 79-100.

Pimenta, M. M. (2014). Juventude e violência. In R. S. Lima, J. L. Ratton, \& R. G. Azevedo (Eds.), Crime, polícia e justiça no Brasil (pp. 265-275). Contexto.

Santo, E. F., \& Scopinho, R. A. (2011). Fora do jogo? jovens negros no mercado de trabalho. Arquivos Brasileiros de Psicologia, 63(spe), 26 -37.

São Paulo, \& Ministério Público do Trabalho. (2018). Pacto pela inclusão social de jovens negras e negros no mercado de trabalho de São Paulo. Ministério Público Do Trabalho. https://www.prt2.mpt.mp.br/images/2018.4/PactopelaInclusaJovensNegroseNegras_final_21.05.pdf

Silva, M. A. (2001). Formação de educadores/as para o combate ao racismo: mais uma tarefa essencial. In E. Cavalleiro (Ed.), Racismo e anti-racismo na educação- repensando nossa escola. Selo Negro.

Silva, M. N. (2006). Nem para todos é a cidade: segregação urbana e racial em São Paulo. Fundação Cultural Palmares.

Sinhoretto, J., \& Morais, D. S. (2018). Violência e racismo: novas faces de uma afinidade reiterada. Revista de Estudios Sociales, 64. https://doi.org/10.7440/res64.2018.02

Souza, M. T. de, Silva, M. D. da, \& Carvalho, R. de. (2010). Integrative review: what is it? How to do it? Einstein (São Paulo), 8(1). https://doi.org/10.1590/s1679-45082010rw1134

Ursi, E. S., \& Gavão, C. M. (2006). Prevenção de lesões de pele no perioperatório: revisão integrativa da literatura. Revista Latino-Americana de Enfermagem, 14(1). https://doi.org/10.1590/S0104-11692006000100017 
Research, Society and Development, v. 10, n. 14, e214101422013, 2021

(CC BY 4.0) | ISSN 2525-3409 | DOI: http://dx.doi.org/10.33448/rsd-v10i14.22013

Valente, R. R. (2017). The vicious circle: effects of race and class on university entrance in Brazil. Race Ethnicity and Education, 20(6). https://doi.org/10.1080/13613324.2016.1150824

Vieira, A. D. S., \& Ostetto, L. C. (2020). 16 anos depois da lei 10.639/03: ouvindo meninos e meninas (negros e não negros) de uma escola do extremo sul catarinense. Revista Saberes Pedagógicos, 4(2). https://doi.org/10.18616/rsp.v4i2. 